\title{
ANALISIS POTENSI DAN EFEKTIVITAS PENERIMAAN PAJAK PENERANGAN JALAN DI KOTA MANADO
}

\author{
Meggy Marchia Pandelaki ${ }^{1}$, Harijanto Sabijono ${ }^{2,}$ Sonny Pangerapan ${ }^{3}$ \\ 1,2,3 jurusan Akuntansi, Fakultas Ekonomi Dan Bisnis, Universitas Sam Ratulangi Manado, Jln Kampus Bahu, \\ Manado 95115, Indonesia \\ E-mail : mgy_cute@yahoo.co.id
}

\begin{abstract}
The street lighting tax is one of the district / city taxes imposed on the use of electricity provided that street lighting is available in the area, whose accounts are paid by the regional government. Street lighting tax is one of the potential sources of regional income that can be influenced by certain factors. Therefore, this study aims to determine the potential and tax effectiveness of street lighting in the Regional Revenue Office of the City of Manado. The analytical method used is qualitative descriptive analysis. The data sources used in this study are secondary data, namely data originating from the Regional Revenue Office of the City of Manado. The results of the study indicate that the potential for street lighting tax in Manado City is less effective, and the tax effectiveness of street lighting from 2013-2017 is very effective. In 2013 the highest effectiveness of street lighting tax was 105.82 with very effective criteria, and in 2016 the lowest effectiveness of street lighting tax was 100.87 with very effective criteria. This means that tax on street lighting is very efficient and good, because the realization of street lighting tax revenues in the city of Manado reaches its real revenue potential.
\end{abstract}

Keywords: Potential, Effectiveness.

\section{PENDAHULUAN}

Konsep pembangunan berpusat pada rakyat memandang inisiatif, kreatif dan rakyat sebagai sumber daya pembangunan yang utama dan memandang kesejahteraan material dan piritual mereka sebagai tujuan yang ingin dicapai oleh proses pembangunan. Pembangunan perekonomian daerah merupakan proses di mana pemerintah dari suatu daerah beserta partisipasi masyarakatnya saling bekerja sama dalam menggunakan sumber daya yang ada dan berupaya semaksimal mungkin untuk mengevaluasi potensi sumber daya tersebut untuk merancang dan membangun perekonomian daerah ke arah yang lebih baik. Dalam melaksanakannya, faktor yang tak kalah penting adalah kemandirian. (Korten, 2013:51).

\section{TINJAUAN PUSTAKA}

Pengertian akuntansi. Pengertian Akuntansi Menurut Kieso, et al. (2016:2) Akuntansi terdiri dari tiga kegiatan yang mendasar yaitu identifikasi, pencatatan dan pengkomunikasian peristiwa ekonomi suatu organisasi kepada pihak yang berkepentingan. Perusahaan mengidentifikasi peristiwa ekonomi sesuai dengan kegiatan usahanya dan mencatat peristiwa tersebut untuk menyediakan catatan kegiatan keuangan.

Pengertian Akuntansi Perpajakan. Akuntansi Pajak Menurut Sukrisno Agoes (2014:10) Akuntansi yang diterapkan sesuai dengan peraturan perpajakan di sebut akuntansi perpajakan. Akuntansi pajak merupakan bagian dari akuntansi komersial yang diatur dalam Standar Akuntansi Keuangan (SAK). Akuntansi pajak hanya mencatat transaksi yang berhubunga dengan perpajakan. Dengan adanya akuntansi pajak WP dapat lebih muda menyusun SPT. Sedangkan akuntansi komersial disusun dan disajikan berdasarkan SAK. 
Namun, untuk kepentingan perpajakan, akutansi komersial harus disesuaikan dengan aturan perpajakan yang berlaku di indonesia.

Konsep Pajak. Menurut Adriani dalam buku Kurnia (2017:26) pajak adalah iuran masyarakat kepada negara (yang dapat dipaksakan) yang terutang oleh yang wajib membayarnya menurut peraturan-peraturan umum (undang-undang) dengan tidak mendapat prestasi kembali yang langsung dapat ditunjuk dan yang gunanya adalah untuk membiayai pengeluaran-pengeluaran umum berhubungan dengan tugas negara untuk menyelenggarakan pemerintahan.

Pengertian Pajak. Pajak merupakan sumber pemasukan keuangan negara dengan cara mengumpulkan dana atau uang dari wajib pajak ke kas negara untuk membiayai pembangunan nasional atau pengeluaran negara lainnya.

Pajak Daerah. Pajak daerah adalah merupakan kontribusi wajib kepada daerah yang terutang oleh orang pribadi atau badan yang bersifat memaksa berdasarkan undang-undang, dengan tidak mendapatkan imbalan secara langsung dan digunakan untuk keperluan daerah bagi sebesar -besarnya kemakmuran rakyat.

Pajak Penerangan Jalan. Berdasarkan Peraturan Daerah No 15 Tahun 2010 yaitu pajak penerangan jalan dipungut atas pengunaan tenaga listrik, baik yang dihasilkan sendiri maupun yang diperoleh dari sumber lain. Pelanggan listrik adalah orang dan atau badan yang menjadi pemilik atau penyewa bangunan rumah dan bangunan lainnya yang mengunakan listrik dari PLN atau bukan PLN.

\section{METODE PENELITIAN}

Jenis Data dan Sumber Data

Jenis Data. Jenis Data yang digunakan untuk penelitian ini adalah deskriptif kualitatif, yaitu jenis data yang bersifat deskriptif atau berbentuk uraian atau penjelasan serta tidak dapat diukur dalam skala numerik. Data kualitatif yang diperlukan dalam penelitian ini berupa data tentang Pajak Penerangan Jalan di Kota Manado.

Sumber Data. Data Primer adalah sumber data penelitian yang diperoleh secara langsung dari sumber aslinya yang berupa wawancara, pendapat dari individu atau kelompok maupun hasil dari observasi dari suatu objek. Data Sekunder adalah Data yang mengacu pada informasi yang dikumpulkan dari sumber yang telah ada. Sumber data sekunder adalah catatan atu dokumentasi perusahaan, publikasi, pemerintah, analisis industri oleh media, situs Web, dan internet. Data yang digunakan dalam penelitian ini adalah data sekunder.

Teknik Pengumpulan Data. Ada beberapa teknik dalam pengumpulan data antara lain :

a. Wawancara yaitu teknik pengumpulan data yang dilakukan dengan cara berkomunikasi lisan yang dilakukan secara terstruktur dengan kepala badan pengelolaan pajak dan retribusi daerah di kota manado besarta karyawan yang ada untuk membahas dan mengali tentang informasi tentang data-data yang diperlukan dalam memecahkan masalah yang dibahas.

b. Metode pengematan langsung yaitu proses pengumpulan data dengan cara mengamati dan mengumpulkan data secara langsung di lokasi penelitian yaitu di badan pengelolaan pajak dan retribusi daerah Kota Manado.

c. Dokumen, yaitu proses pengumpulan data dengan mempelajari dan menganalisis dokumen yang berkaitan dengan pajak hotel.

d. Studi kepustakaan, yaitu kegiatan untuk menghimpun informasi yang relevan dengan topik atau masalah yang menjadi objek penelitian.

Dalam penelitian ini, data yang digunakan adalah wawancara, observasi, pengumpulan dokumen, dan studi kepustakaan. 
Metode Analisis. Jenis penelitian ini menggunakan penelitian deskriptif kualitatif. Deskriptif kualitatif merupakan penelitian yang bertujuan untuk memahami fenomena tentang apa yang dialami oleh subjek penelitian. Misalnya perilaku, persepsi, motivasi, tindakan dan lain-lain secara holistik dan dengan cara deskripsi dalam bentuk kata-kata dan bahasa, pada suatu konteks khusus yang alamiah dan dengan memanfaatkan berbagai metode alamiah.

\section{HASIL ANALISIS DAN PEMBAHASAN}

4.1. Gambaran Umum dan Sejarah Kota Manado

Kota Manado yaitu Ibukota Provinsi Sulawesi Utara sekaligus merupakan kota terbesar yang ada di Sulawesi Utara yang memiliki luas wilayah sekitar 15.726 Ha. Namun, dengan adanya program reklamasi Pantai Teluk Manado, luas daratannya telah bertambah kurang lebih seluas $67 \mathrm{Ha}$, sedangkan untuk wilayah kepulauan meliputi Pulau Bunaken, Pulau Manado Tua yang ketiganya merupakan objek wisata adalah Kota Manado. Berdasarkan penelitian yang dilakukan maka penulis dapat memperoleh data-data dari beberapa sumber di antaranya dari Badan Pengelola Pajak dan Retribusi Daerah Kota Manado. Adapun data-data yang diperoleh adalah Potensi dan Efektivitas Pajak Penerangan Jalan di Kota Manado Tahun 2013-2017.

Tabel 1. Perhitungan Potensi Pajak Penerangan Jalan Kota Manado Tahun 2013-2017

\begin{tabular}{rrrr}
\multicolumn{1}{l}{ Tahun } & Basis Penerangan Jalan & $\begin{array}{c}\text { Tarif Pajak } \\
\text { Penerangan } \\
\text { Jalan }\end{array}$ & $\begin{array}{c}\text { Potensi Penerimaan Pajak } \\
\text { Penerangan Jalan }\end{array}$ \\
\hline 2013 & 37.000 .000 .000 & $10 \%$ & 3.700 .000 .000 \\
2014 & 43.000 .000 .000 & $10 \%$ & 4.300 .000 .000 \\
2015 & 49.000 .000 .000 & $10 \%$ & 4.900 .000 .000 \\
2016 & 50.000 .000 .000 & $10 \%$ & 5.000 .000 .000 \\
2017 & 56.750 .000 .000 & $10 \%$ & 5.675 .000 .000 \\
Total & 235.750 .000 .000 & & 23.575 .000 .000 \\
\hline
\end{tabular}

Sumber : Data Diolah, 2018

Berdasarkan perhitungan, Jumlah Potensi Penerimaan Pajak Penerangan Jalan Tahun 2013 adalah sebesar Rp3.700.000.000,00. Pada Tahun 2014 Jumlah Potensi Penerimaan Pajak Penerangan Jalan adalah sebesar Rp4.300.000.000,00. Pada Tahun 2015 Jumlah Potensi Pajak Penerangan Jalan yaitu sebesar Rp4.900.000.000,00. Pada Tahun 2016 Jumlah Potensi Penerimaan Pajak Penerangan Jalan adalah sebesar Rp5.000.000.000,00. Pada Tahun 2017 Jumlah Potensi Penerimaan Pajak Penerangan Jalan adalah sebesar Rp5.675.000.000,00.

\section{Perhitungan Efektivitas Pajak Penerangan Jalan}

Tabel 2. Target dan Realisasi Pajak Penerangan Jalan di Kota Manado tahun 2013-2017

\begin{tabular}{lrr}
\hline Tahun & Target & Realisasi \\
\hline 2013 & 37.000 .000 .000 & 39.153 .504 .554 \\
2014 & 43.000 .000 .000 & 44.916 .556 .996 \\
2015 & 49.000 .000 .000 & 50.557 .318 .490 \\
2016 & 50.000 .000 .000 & 50.435 .147 .574 \\
2017 & 56.750 .000 .000 & 59.724 .290 .560 \\
\hline
\end{tabular}

Sumber : PAD Kota Manado, 2018 
Untuk menghitung Efektivitas dari Pajak Penerangan Jalan di Kota Manado, maka rumusnya adalah sebagai berikut :

$$
\text { Efektivitas }=\frac{\text { Realisasi Penerimaan Pajak }}{\text { Target Penerimaan Pajak }} \times 100 \%
$$

Tahun 2013. Berdasarkan jumlah target penerimaan pajak penerangan jalan sebesar Rp37.000.000.000,00 diketahui efektivitas pajak penerangan jalan di Kota Manado Tahun 2013 dengan realisasi penerimaan pajak penerangan jalan sebesar Rp39.153.504.554,00 Tahun 2013 adalah sebagai berikut :

$$
\frac{39.153 .504 .554}{37.000 .000 .000} \times 100 \%=105,82
$$

Tahun 2014. Berdasarkan jumlah target penerimaan pajak penerangan jalan sebesar Rp43.000.000.000,00 diketahui efektivitas pajak penerangan jalan di Kota Manado Tahun 2014 dengan realisasi penerimaan pajak penerangan jalan sebesar Rp44.916.556.996,00 Tahun 2014 adalah sebagai berikut :

$$
\frac{44.916 .556 .996}{43.000 .000 .000} \times 100 \%=104,46
$$

Tahun 2015. Berdasarkan jumlah target penerimaan pajak penerangan jalan sebesar Rp49.000.000.000,00 diketahui efektivitas pajak penerangan jalan di Kota Manado Tahun 2015 dengan realisasi penerimaan pajak penerangan jalan sebesar Rp50.557.318.490,00 Tahun 2015 adalah sebagai berikut :

$$
\frac{50.557 .318 .490}{49.000 .000 .000} \times 100 \%=103,18
$$

Tahun 2016. Berdasarkan jumlah target penerimaan pajak penerangan jalan sebesar Rp50.000.000.000,00 diketahui efektivitas pajak penerangan jalan di Kota Manado Tahun 2016 dengan realisasi penerimaan pajak penerangan jalan sebesar Rp50.435.147.574,00 Tahun 2016 adalah sebagai berikut :

$$
\frac{50.435 .147 .574}{50.000 .000 .000} \times 100 \%=100,87
$$

Tahun 2017. Berdasarkan jumlah target penerimaan pajak penerangan jalan sebesar Rp56.750.000.000,00 diketahui efektivitas pajak penerangan jalan di Kota Manado Tahun 2017 dengan realisasi penerimaan pajak penerangan jalan sebesar Rp59.724.290.560,00 Tahun 2017 adalah sebagai berikut :

$$
\frac{59.724 .290 .560}{56.750 .000 .000} \times 100 \%=105,24
$$

\subsection{Pembahasan}

Analisis Potensi Penerimaan Pajak Penerangan Jalan di Kota Manado. Dari hasil perhitungan potensi selama lima tahun, yaitu periode Tahun 2013-2017, total Potensi Penerimaan Pajak Penerangan Jalan adalah sebesar Rp23.575.000.000,00. 
Tabel 3. Perbandingan Target Penerimaan dan Potensi Penerimaan Pajak Penerangan Jalan di Kota Manado tahun 2013-2017

\begin{tabular}{lccc}
\hline Tahun & $\begin{array}{c}\text { Target Penerimaan } \\
\text { Pajak Penerangan } \\
\text { Jalan }\end{array}$ & $\begin{array}{c}\text { Realisasi Penerimaan } \\
\text { Pajak Penerangan } \\
\text { Jalan }\end{array}$ & $\begin{array}{c}\text { Potensi Penerimaan } \\
\text { Pajak Penerangan } \\
\text { Jalan }\end{array}$ \\
\hline 2013 & 37.000 .000 .000 & 39.153 .504 .554 & 3.700 .000 .000 \\
2014 & 43.000 .000 .000 & 44.916 .556 .996 & 4.300 .000 .000 \\
2015 & 49.000 .000 .000 & 50.557 .318 .490 & 4.900 .000 .000 \\
2016 & 50.000 .000 .000 & 50.435 .147 .574 & 5.000 .000 .000 \\
2017 & 56.750 .000 .000 & 59.724 .290 .560 & 5.675 .000 .000 \\
Total & 235.750 .000 .000 & 244.786 .818 .284 & 23.575 .000 .000 \\
\hline
\end{tabular}

Sumber : Data Diolah, 2018

Apabila dibandingkan dengan perhitungan target yang dibuat oleh Dinas Pendapatan Daerah Kota Manado berdasarkan tabel 4.3 jumlah potensi penerimaan dari hasil perhitungan potensi dan target penerimaan Pajak Penerangan Jalan yang dibuat oleh Dispenda sudah mencapai target dari realisasinya. Terdapat selisih sebesar Rp9.036.818.284,00 antara target dan realisasi, dan dapat dilihat jika di total keseluruhan dan dibandingkan dengan pengrealisasian penerimaan pajak bisa dikatakan bahwa penerimaan atas pajak penerangan jalan di Kota Manado sangatlah efektif.

Analisis Efektivitas Pajak Penerangan Jalan di Kota Manado. Dari semua hasil perhitungan efektivitas pajak penerangan jalan yang diperoleh dari Tahun 2013-2017 diketahui bahwa efektivitas Pajak Penerangan Jalan di Kota Manado untuk periode Tahun 2013-2017 sangatlah efektif.

Tabel 4. Efektivitas Pajak Penerangan Jalan di Kota Manado Tahun 2013-2017

\begin{tabular}{ccc}
\hline Tahun & $\begin{array}{c}\text { Efektivitas Pajak Penerangan } \\
\text { Jalan (persen) }\end{array}$ & Kriteria \\
\hline 2013 & 105,82 & Sangat Efektif \\
2014 & 104,46 & Sangat Efektif \\
2015 & 103,18 & Sangat Efektif \\
2016 & 100,87 & Sangat Efektif \\
2017 & 105,24 & Sangat Efektif \\
\hline
\end{tabular}

Sumber : Diolah 2018

Efektivitas Pajak Penerangan Jalan di Kota Manado menunjukkan bahwa pemungutan dan pengelolaan Pajak Penerangan Jalan di Kota Manado sudah sangat efektif pada Kurun Waktu periode Tahun 2013-2017. Hal ini dikarenakan realisasi Pajak Penerangan Jalan di Kota Manado mencapai potensi penerimaan riilnya. Untuk ke depannya diharapkan Pemerintah Daerah Kota Manado harus mempertahankan nilai efektif yang sudah di dapat sehingga telah mencapai potensi penerimaan riilnya, karena pajak penerangan jalan sangatlah berpotensi bagi penerimaan pendapatan daerah dan bisa meningkatkan penerimaan pajak penerangan jalan agar efektif. Pajak ini lebih efektif bahkan sangat efektif agar penerimaannya senantiasa dapat di tingkatkan dari tahun ke tahun. 


\section{KESIMPULAN DAN SARAN}

\subsection{Kesimpulan}

Penelitian ini dimaksudkan untuk menganalisis potensi penerimaan dan efektivitas pajak penerangan jalan di Kota Manado. Dari analisis data yang telah di lakukan dapat di ambil kesimpulan sebagai berikut :

1. Potensi penerimaan Pajak Penerangan Jalan Kota Manado pada tahun 2013 adalah sebesar Rp3.700.000.000,00. Pada Tahun 2014 Jumlah Potensi Penerimaan Pajak Penerangan Jalan adalah sebesar Rp4.300.000.000,00. Pada Tahun 2015 Jumlah Potensi Penerimaan Pajak Penerangan Jalan adalah sebesar Rp4.900.000.000,00. Pada Tahun 2016 Jumlah Potensi Penerimaan Pajak Penerangan Jalan adalah sebesar Rp5.000.000.000,00. Pada Tahun 2017 Jumlah Potensi Penerimaan Pajak Penerangan Jalan adalah sebesar Rp5.675.000.000,00. Hasil perhitungan Potensi Penerimaan Pajak Penerangan Jalan menunjukkan bahwa penerimaan Pajak Penerangan Jalan di Kota Manado kurang efektif di karenakan target yang ditentukan oleh Badan Pengelola Pajak dan Retribusi Daerah terlalu rendah, sehingga mengakibatkan terjadinya potensi yang kurang optimal.

2. Efektivitas penerimaan Pajak Penerangan Jalan Kota Manado pada tahun 2013 sebesar 105,82 dengan kriteria sangat efektif. Pada tahun 2014 sebesar 104,46 dengan kriteria sangat efektif. Pada tahun 2015 sebesar 103,18 dengan kriteria sangat efektif. Pada tahun 2016 sebesar 100,87 dengan kriteria sangat efektif. Pada tahun 2017 sebesar 105,24 dengan kriteria sangat efektif, sehingga realisasi akan pajak penerangan jalan berjalan dengan efektif. Setiap tahunnya efektivitas pajak penerangan jalan selalu mengalami peningkatan yang sangat efektif. Hal ini dikarenakan realisasi penerimaan Pajak Penerangan Jalan di Kota Manado mencapai potensi penerimaan riilnya. Hasil perhitungan efektivitas Pajak Penerangan Jalan menunjukkan bahwa penerimaan Pajak Penerangan Jalan di Kota Manado sudah sangat efektif atau mencapai target yang ditentukan oleh Dinas Pendapatan Daerah Kota Manado pada tahun 2013 hingga tahun 2017.

\subsection{Saran}

Berdasarkan hasil penelitian dan pembahasan yang dilakukan penulis, maka sebagai bahan pertimbangan agar potensi penerimaan dan efektivitas pajak penerangan jalan dapat lebih optimal, maka dari itu diperlukan lagi beberapa penyempurnaan atas kekurangan yang ada sebelumnya. Untuk itu penulis mengemukakan saran sebagai berikut.

1. Potensi Penerimaan Pajak Penerangan Jalan di Kota Manado masih sangat kurang sehingga pemerintah harus lebih memperhatikan dan mencari solusi atau cara dalam meningkatkan Potensi Penerimaan Pajak Penerangan Jalan di Kota Manado dengan cara menggali potensi-potensi yang ada, mencari jaringan dari luar kota bahkan dari luar daerah untuk peningkatan pembangunan penerangan jalan yang ada di Kota Manado.

2. Badan Pengelola Pajak dan Retribusi Daerah di Kota Manado diharapkan terus meningkatkan kinerjanya agar profesionalitas pekerjaan terus membaik dan tingkat efektivitas yang sudah baik tetap terus konsisten agar tingkat efektivitas terus meningkat setiap tahunnya.

\section{DAFTAR PUSTAKA}

Agoes Sukrisno, 2014. Akuntansi Perpajakan. Edisi 3, Salemba Empat, Jakarta.

Francesco Marino, Fabio Leccese, Stefano Pizzuti, 2017. Adaptive Street Lighting Predictive Control. 
Jullie J. Sondakh, Ibrahim Driyana, Wangkar Aneke, 2016. Analisis Perbandingan Potensi Penerimaan dan Efektivitas Pajak Penerangan Jalan Kabupaten Minahasa Tenggara. Fakultas Ekonomi dan Bisnis, Universitas Sam Ratulangi Manado.

Korten, Tatok Mardikanto, Poerwoko Soebianto, 2013. Konsep Pembangunan Masyarakat.

Leo Agung Danang Dwi Pangestu, S.E, 2017. Perpajakan Brevet A\&B, Penerbit CAPS (Center for Academic Publishing Service).

Marihot Pahala Siahaan, S.E, M.T, 2016. Pajak Daerah dan Retribusi Daerah.

Mustainnatul Lailia, 2016. Analisis Potensi Penerimaan, Efektivitas, dan Tax Effort Pajak Penerangan Jalan di Kabupaten Lumajang.

Priantara Diaz, 2013. Perpajakan Indonesia. Edisi 2 Revisi, Penerbit Mitra Wacana Media, Jakarta.

Prof. Dr. Mardiasmo, MBA, Ak, 2018. Perpajakan. Edisi Terbaru, Penerbit Andi, Yogyakarta.

Prof. Supramono Theresia Woro Damayanti, 2015. Perpajakan Indonesia Mek anisme dan Perhitungan. Penerbit Andi, Yogyakarta, Edisi Revisi.

Rangga Bawono Amindara, 2016. Devinisi Pajak Daerah.

Simanjuntak, 2013. Definisi Otonomi Daerah.

Simanjuntak, 2013. Otonomi Pemerintahan Daerah yang dapat mengelola daerah dengan baik.

Subadriyah, S.E, M.Si, 2017. Pajak Penghasilan. Penerbit Pustaka Pelajar dan UNISNUPRESS.

Syaiful Amri, 2016. Analisis Efektivitas dan Kontribusi Pajak Penerangan Jalan Terhadap Pendapatan Asli Daerah Kota Pekalongan.

Yi Jiang, Shuo Li, Bowen Guan, Guangyuan Zhao, 2015. Cost Effectiviness of New Roadway Lighting System. 